\title{
Return to play following muscle injuries in professional footballers
}

Anna Hallen and Jan Ekstrand

\section{Linköping University Post Print}

\section{Tweet}

N.B.: When citing this work, cite the original article.

This is an electronic version of an article published in:

Anna Hallen and Jan Ekstrand, Return to play following muscle injuries in professional footballers, 2014, Journal of Sports Sciences, (32), 13, 1229-1236.

Journal of Sports Sciences is available online at informaworldTM:

http://dx.doi.org/10.1080/02640414.2014.905695

Copyright: Taylor \& Francis: SSH Journals http://www.tandf.co.uk/journals/default.asp

Postprint available at: Linköping University Electronic Press http://urn.kb.se/resolve?urn=urn:nbn:se:liu:diva-110291 
Running title: Return to play after muscle injuries.

Type of article: Original research

\section{Return to play following muscle injuries in professional}

\section{footballers}

Anna Hallen ${ }^{1}$, Jan Ekstrand ${ }^{2}$

${ }^{1}$ Department of Medical and Health Sciences, Football Research Group, Linköping

University, Linköping, Sweden

info.frg@telia.com

${ }^{2}$ Department of Medical and Health Sciences, Football Research Group, Linköping

University, Linköping, Sweden

jan.ekstrand@telia.com

Corresponding author:

Jan Ekstrand MD, PhD

Solstigen 3, S-589 43, Linköping, Sweden

Tel.: + 4613 161648, fax: +4613161892

jan.ekstrand@telia.com

Keywords: Hamstring, thigh muscle injury, MRI, imaging, re-injury

Word count: 3131

Abstract: 195 words 
Running title: Return to play after muscle injuries.

\begin{abstract}
This prospective cohort study described return-to-play (RTP) data for different types of muscle injuries in male elite level football players in Europe. Eighty-nine European professional teams were followed between 2001 and 2013. Team medical staff recorded individual player exposure and time-loss injuries. A total of 17,371 injuries occurred, including 5603 (32\%) muscle injuries. From 2007, we received results from 386 magnetic resonance imaging (MRI) examinations, and radiological grading was performed. A negative MRI was associated with shorter recovery time (6 \pm 7 days). Lay-off days were correlated with MRI grading of thigh muscle injuries $(P<0.001)$. Among hamstring injuries, $83 \%$ occurred to the biceps femoris, $12 \%$ affected the semimembranosus, and $5 \%$ the semitendinosus. Recurrence rate was higher among biceps femoris injuries (18\%) compared to semitendinosus and semimembranosus injuries (2\% together). Groin muscle injuries caused shorter median absence ( 9 days) than hamstring (13 days; $P<0.001)$, quadriceps (12 days; $P$ $<0.001$ ), and calf muscle (13 days; $P<0.001)$ injuries. Overall, we found that MRI was valuable for prognosticating RTP, with radiological grading associated with lay-off times after injury. Re-injuries were common in biceps femoris injuries but rare in semitendinosus and semimembranosus injuries.
\end{abstract}


Running title: Return to play after muscle injuries.

\section{Introduction}

Athletes participating in professional football have a substantial risk of injury, which has been estimated to be about 1000 times higher than for typical industrial occupations that are generally regarded as high-risk (Drawer \& Fuller, 2002). Injury avoidance and keeping players on the pitch is critical for performance and for economic reasons. Compared to those that manage injuries less effectively, teams that can avoid or minimize injuries have a greater chance of success, as evaluated by the final position in the league system (Árnason, et al., 2004; Eirale, Tol, Farooq, Smiley, \& Chalabi, 2012; Hägglund, et al., 2013). From an economic aspect, the average cost of a first team player being injured for one month is around 500,000 Euros (Ekstrand, 2013a).

Medical RTP decisions can be difficult to make, but some guidelines have been prepared using databases from large injury studies, including the UEFA Champions League (UCL) Injury Study, an on-going detailed longitudinal study for over 12 years, which documents the types and frequencies of injuries incurred by teams of the UEFA Champions League (Ekstrand, 2013b; Ekstrand, Hägglund, Kristenson, Magnusson, \& Waldén, 2013; Ekstrand, Hägglund, \& Waldén, 2011b). The UCL injury study is the primary source of evidence-based data regarding injuries in male professional club football, and its main findings can help medical teams improve estimates of when players can return to training and matches after specific injuries.

Muscle injuries constitute almost one-third of all time-loss injuries among male elite football players, and account for over one-fourth of all injury-related lay-off time ( Ekstrand, Hägglund, \& Waldén, 2011a; Ekstrand, et al., 2011b). However, muscle injuries are a heterogeneous group, including many different types, locations, severities, and sizes of muscle injury, and they are described using a wide range of differing terminology. To be able to make a prognosis regarding healing time and rehabilitation, muscle injuries must be 
Running title: Return to play after muscle injuries.

classified into different groups, and large bodies of data are needed to make reliable statements (Ekstrand, et al., 2012). The present study aimed to describe return-to-play data for different types of muscle injuries in male elite level football players in Europe. Our hypothesis was that imaging would provide detailed data that would assist the persons working on the football field in answering the common question "When can the player return to ordinary training and matches?" 
Running title: Return to play after muscle injuries.

\section{Material and methods}

\section{Study population}

Between July 2001 and June 2013, 89 male professional football teams from the top divisions of 17 countries in Europe were prospectively monitored over one to twelve seasons, during the full football season, as well as the pre-season. All contracted players for the first teams were invited to participate in the study, and all accepted. Players who left the team during the season, e.g. because of transfer, were only included while they were with the team. The full methodology and the validation are reported elsewhere (Hägglund, Waldén, Bahr, \& Ekstrand, 2005).

\section{Study procedure and validity}

The study design underwent an ethical review and was approved by the UEFA Football Development Division and the Medical Committee. The procedure followed the guidelines established by FIFA's (Fédération Internationale de Football Associations) consensus document (Fuller, et al., 2006) and by UEFA (Union of European Football Associations) (Hägglund, et al., 2005). To ensure that information was reliably recorded, the teams were provided with a study manual containing definitions and describing the correct procedures for recording data. The definitions used are provided in Table 1. To avoid language problems, the manual and study forms were translated from English into French, Italian, Spanish, German, and Russian. Additionally, we checked all reports each month and sent feedback to the teams to enable correction of any missing or unclear data.

Baseline data for the players was collected yearly, at the start of each season. Individual player participation in training and matches (minutes of exposure) was registered by the club contact person on a standard exposure form sent to the study group on a monthly basis. This included exposures with the first and second team, as well as any national team exposure, for 
Running title: Return to play after muscle injuries.

all players. We also received a monthly Standard Injury Form, on which the team medical staff recorded player injuries. This form provided information about the diagnosis, nature, and circumstances of the injury. Recorded injuries included any event resulting in the player being unable to train fully or to play matches (time-loss injuries), and the player was considered injured until the team's medical staff allowed full training and declared him available for match selection. All injuries were monitored until the final day of rehabilitation. Return to play (RTP) was defined according to the Consensus Statement developed by the collaborative effort of organisations such as the American Academy of Orthopaedic Surgeons and American College of Sports Medicine as follows: "The decision-making process of returning an injured or ill athlete to practice or competition. This ultimately leads to medical clearance of an athlete for full participation in sports" (Herring, Kibler, \& Putukian, 2012). Specific muscle injuries were classified based on the Orchard Sports Injury Classification System (OSICS) (Orchard, 1993) .

****Table 1 around here****

\section{Magnetic resonance imaging}

From the 2007/08 season and onwards, information about examination and imaging of thigh muscle injuries has been obtained for 1653 injuries from 38 clubs in ten countries (Figure 1). Twenty-one teams agreed to send us magnetic resonance (MRI) imaging of thigh muscle injuries. For this study, the clubs were instructed to perform the initial MRI examination within 24-48 hours of the injury event. Additionally, the MRI machine was not to be older than five years and had to have a field strength of at least 1.5 Tesla. The minimum MR sequences included axial and coronal planes using T1, T2 with fat saturation, and/or STIR sequences. A MRI Thigh Injury Report Form was created with information including the date 
Running title: Return to play after muscle injuries.

of imaging, name of radiologist evaluating the images, MR sequences used, muscles involved, and severity of injury. If more than one muscle was injured, the muscle with the most extensive pathology was denoted as the primary muscle involved, and assessment criteria were used for that particular muscle.

Severity classification was performed using a modification of Peetrons classification (Peetrons, 2002) with the following grading system: grade 0, negative MRI without any visible pathology; grade 1, oedema but no architectural distortion; grade 2, architectural disruption indicating partial tear; and grade 3, total muscle or tendon rupture. The teams used PACSMail ${ }^{\circledR}$ (www.sybermedica.com) to send their MRIs for on-line review by two independent radiologists who were unaware of clinical details other than the suggested hamstring injury.

Figure 1 around here

\section{Analyses}

Lay-off times are presented as both mean $\pm \mathrm{SD}$, and median with corresponding IQR. Due to skewed distributions in lay-off times, group differences were analysed using non-parametric methods, including Kruskal-Wallis test for the overall between-group difference and MannWhitney U-test for all pair-wise comparisons. Bonferroni correction was used to adjust the significance level for multiple pair-wise comparisons, controlling for type I error. The critical value of 0.05 was divided by the number of tests conducted. Association between categorical variables was measured with Pearson's chi-square test or Fisher's exact test. The significance level was set at $P<0.05$. All statistical analyses were performed using IBM SPSS Statistics 21.0. 
Running title: Return to play after muscle injuries.

\section{Results}

A total of 17,371 injuries were recorded, of which 5603 (32\%) were muscle injuries. Table 2 presents the numbers and percentages of all muscle injuries, as well as their recurrence rates and their mean and median lay-off days before full participation in team training.

\section{Injuries by location}

The four most common OSICS diagnoses were hamstring injury/tear (34\%), groin injury/pain adductor group (21\%), quadriceps injury/tear (14\%), and calf muscle injury (12\%). These four diagnoses accounted for $81 \%$ of all muscle injuries, and $88 \%$ of all lay-off days for muscle injuries. Lay-off days were significantly associated with muscle injury location according to OSICS $(P<0.001)$, with the groin injury/pain adductor group causing significantly shorter lay-off time (median, 9; IQR, 11 days) compared to hamstring (median, 13; IQR, 15 days; $P<$ 0.001), quadriceps (median, 12; IQR, 16 days; $P<0.001$ ), and calf muscle (median, 13; IQR, 16 days; $P<0.001)$ injuries. In total, $95 \%$ of all muscle injuries affected these four locations.

\section{Radiological grades of injury and lay-off time for thigh injuries}

Figure 1 shows that 1653 hamstring injuries were recorded from 2007 to 2013 . Of these, 920 (56\%) were examined by MRI and 377 (41\%) also had concomitant initial ultrasound. Only an initial ultrasound without MRI was performed for 475 injuries (29\%), while the remaining $234(14 \%)$ were examined clinically without the use of any imaging. We received MRI forms for 386 MRI examinations. The majority $(68 \%)$ of the MRI examinations received by the study group were reviewed by the 2 independent radiologists and there was a strong agreement between their reports, the kappa value being over $90 \%$. Of the MRI examinations received, 35 injuries $(9 \%)$ were radiological Grade 0 injuries with no visible pathology on 
Running title: Return to play after muscle injuries.

MRI, including 34 to hamstring muscles and only one to the quadriceps. The mean absence for grade 0 injuries was $9 \pm 7$ days, with a median of 8 days.

Table 3 displays the results from the 249 hamstring muscle injuries with pathology visible on MRI (grades 1-3 according to Peetrons). The majority of hamstring injuries occurred to the biceps femoris (83\%), while $12 \%$ affected the semimembranosus and $5 \%$ the semitendinosus. No difference in lay-off days was detected between the hamstring muscle injury subgroups $(P=0.828)$. Among hamstring muscle injuries, we observed a significant association between lay-off days and MRI grading $(P<0.001)$. Pair-wise comparisons revealed significant differences between grade 1 (median, 15; IQR, 14 days) and grade 2 (median, 21; IQR, 19 days; $P<0.001$ ), between grade 1 and grade 3 (median, 37; IQR, 59 days; $P<0.001)$ and between grade 2 and $3, P<0.001$.

Table 4 shows the 102 quadriceps muscle injuries with pathology visible on MRI (grades 1-3 according to Peetrons). There was a significant association between lay-off days and MRI grading among quadriceps muscle injuries $(P<0.001)$. Pair-wise comparisons showed significant differences between grade 1 (median, 12; IQR, 9 days) and grade 2 (median, 22; IQR, 29 days; $P<0.001$ ), between grade 1 and grade 3 (median, 67; IQR, 27 days; $P<0.001)$, and between grade 2 and grade $3(P<0.004)$.

\section{Re-injuries}

The average recurrence rate was $15 \%$ for the four most common OSICS diagnoses. We found a significant association between recurrence rate and these diagnoses $(P=0.035)$. The recurrence rate was higher in the groin injury/pain adductor group than among calf muscle injuries $(18 \%$ vs. $13 \% ; P=0.06)$. There was also a significant association between recurrence rate and the hamstring muscle injury subgroups $(P=0.028)$. Recurrence of injuries to the biceps femoris was common (18\%), while re- injuries to the semitendinosus and 
Running title: Return to play after muscle injuries.

semimembranosus were rare (2\% together). We observed no significant association of recurrence rate with MRI grading of hamstring or quadriceps muscle injuries. 
Running title: Return to play after muscle injuries.

\section{Discussion}

The strength of this study is the analysis of a large number of muscle injuries from a homogenous population of professional male footballers. This large body of study material enabled the separation of injuries into subgroups, while still having mostly robust data. Detailed information about lay-off times and recurrence rates is of great practical use for football medical staffs (Ekstrand, 2013a).

\section{Groin muscle injuries cause shorter absence}

A main finding of this study was that groin muscle injuries caused shorter absence than injuries to hamstrings, quadriceps, and calves. This could be due to the overuse nature of many groin injuries, and absences due to overuse injuries tend to be shorter than those due to traumatic injuries (Gajhede Knudsen, Ekstrand, Magnusson, \& Maffulli, 2013). We found no differences in lay-off days following injuries to hamstrings, quadriceps, and calves, with each leading to a median absence of $12-13$ days.

\section{The majority of hamstring injuries affect the biceps femoris muscle}

Our finding that most hamstring injuries affected the biceps femoris muscle was consistent with previous studies in Australian football (Connell, et al., 2004; Koulouris, Connell, Brukner, \& Schneider-Kolsky, 2007). Furthermore, in accordance with the findings of Slavotinek et al. (Slavotinek, Verrall, \& Fon, 2002), we found no relationship between the specific muscle involved and the lay-off time.

\section{MRI grading of thigh muscle injuries relates to lay-off time}

Of greater clinical importance, we found that the MRI grading of thigh muscle injuries was closely associated with lay-off times and useful in prognosticating absence. This finding 
Running title: Return to play after muscle injuries.

implies that at the elite level, team medical staffs can use imaging as a helpful tool for prognosticating absence after muscle injuries. This is also underlined by the fact that over $80 \%$ of all muscle injuries were radiologically investigated, either by MRI or sonography. While clinical examination is the basis for diagnosis, at the professional level, different imaging techniques are frequently $(>80 \%)$ used to enhance the diagnosis quality in order to better prognosticate healing time and duration of lay-off from football. Ekstrand et al. (2012) showed that MRI grades of hamstring muscle injuries are highly associated with the time of absence from football. An MRI examination performed 24-48 hours after a muscle injury can provide information about how long of an absence is to be expected. Several studies, mainly from Australian Rules football, have also indicated the possibility of using MRI to prognosticate lay-off time after hamstring injury (Askling, Saartok, \& Thorstensson, 2006; Cohen, et al., 2011; Comin, Malliaras, Baquie, Barbour, \& Connell; Ekstrand, Askling, Magnusson, \& Mithoefer, 2013; Ekstrand, et al., 2012; Gibbs, Cross, Cameron, \& Houang, 2004; Koulouris \& Connell, 2006; Koulouris, et al., 2007; Schneider-Kolsky, Hoving, Warren, \& Connell, 2006; Slavotinek, 2010; Slavotinek, et al., 2002; Verrall, Slavotinek, Barnes, Fon, \& Esterman, 2006).

Our data showed that a negative MRI was associated with shorter recovery time, normally around 6-9 days. Several studies have demonstrated that negative MRI findings in clinically suspected hamstring muscle injuries are associated with shorter recovery time (Connell, et al., 2004; Ekstrand, Askling, et al., 2013; Ekstrand, et al., 2012; Gibbs, et al., 2004; Koulouris \& Connell, 2006; Slavotinek, et al., 2002; Verrall, Slavotinek, Barnes, Fon, \& Spriggins, 2001). These findings suggest that clinically diagnosed hamstring injuries with negative MRI results have a good prognosis.

One might wonder why MRIs are performed even following these minor injuries with short lay-offs. The main reason is that even a minor injury could be initially associated with 
Running title: Return to play after muscle injuries.

substantial pain, leading the clinician to suspect a more severe injury. A negative MRI helps the medical staff in prognosticating the absence, and permits a more rapid rehabilitation. The cause of posterior thigh injury where MRI shows no pathology is not fully understood. It is possible that these cases involve subtle muscle injury that is below the sensitivity of MRI detection (Verrall, Kalairajah, Slavotinek, \& Spriggins, 2006). Another possibility is that players could have an alternative diagnosis, such as back-related problems, neural tension, or muscle spasm (Connell, et al., 2004; Koulouris, et al., 2007; Müller-Wohlfahrt, Ueblacker, \& Hänsel, 2013; Müller-Wohlfahrt, Ueblacker, \& Hänsel, 2010).

\section{Higher risk of re-injury for biceps femoris}

As previously reported, we found that hamstring injury recurrence was common, and that previous injury was an important risk factor for new hamstring injury (Árnason, et al., 2004; Gabbe, Bennell, Finch, Wajswelner, \& Orchard, 2006; Garrett, 1996; Hägglund, Waldén, \& Ekstrand, 2006; Verrall, et al., 2001; Woods, et al., 2004). Here we found that the re-injury rates differed among the individual muscles in the hamstring group. The recurrence of injuries to the biceps femoris was common (18\%) while re-injuries to the semitendinosus and semimembranosus were rare $(2 \%$ together). This finding raises the question of whether rehabilitation methods and timing should differ between injuries to the biceps femoris (perhaps leaning towards safer rather than quicker recovery) versus to the semitendinosus and semimembranosus (where accelerated rehabilitation may be acceptable).

\section{Limitations}

One limitation of this study was that our study population was limited to male professional football players; therefore, our findings may not necessarily reflect the injury characteristics within a more general population or at other levels of play. Also, of the 920 MRI 
Running title: Return to play after muscle injuries.

examinations carried out, only 386 (42\%) MRI results from 21 clubs were sent to the study group. The majority of MRI examinations (58\%) were not sent to us, mainly due to the fact that 17 clubs were not willing to send MRI results outside their club.

Additionally, the MRIs were examined by several radiologists from different countries. Our study included an agreement about how and when MRIs should be executed, and used a standard MRI form; however, the inter-observer reliability between the different radiologists is unknown. It must also be noted that muscle injuries are a heterogeneous group, and injuries to different muscle groups behave differently. The present study group included muscle injuries of different size, types, and intramuscular locations. Further classification subgrouping of muscle injuries might be of additional value in prognosticating absence (Ekstrand, Askling, et al., 2013; Ekstrand, et al., 2011a; Müller-Wohlfahrt, et al., 2013; Müller-Wohlfahrt, et al., 2012).

Finally, as pointed out by Connell et al. (2004), the RTP of football players to full training also depends on external factors, including e. g. player management in the club, physical and mental characteristics of the player, and medical history (Comin, et al.; Connell, et al., 2004), and such factors were not evaluated in this study. Ideally, an RTP decision is made as an agreement between different stakeholders in a team, such as team doctors, physiotherapists, and coaches. However, sometimes RTP decision making may lead to conflicts between coaches and medical teams (Shrier, Safai, \& Charland, 2014). In 2005, Orchard et al. called for guidelines for RTP following muscle injuries and proposed that it may be a sensible strategy to allow earlier RTP in team sports and accept a low-to-moderate injury recurrence rate. 
Running title: Return to play after muscle injuries.

\section{Conclusions}

Muscle injuries constitute a heterogeneous group with different behaviour, complicating the prognostication of RTP, and making it important to classify muscle injuries into subgroups for proper evaluation. Large studies are needed to obtain robust and reliable data relating to RTP after muscle injuries. To our knowledge, the present study analyses the largest available set of muscle injuries among elite level male football players. The presented data should be helpful in producing guidelines for team medical staffs wanting to prognosticate absence after muscle injuries. We find that clinical diagnosis is of primary importance, but imaging is valuable for prognosticating RTP, as radiological grading is associated with lay-off times after injury. Our data further show that re-injuries are common in biceps femoris injuries, but rare in injuries to semitendinosus and semimembranosus and not prognosticable by MRI.

\section{Acknowledgments}

The authors wish to thank the participating clubs, medical staffs, and players. The statistical advice of Henrik Magnusson (Msc) is also gratefully acknowledged. 
Running title: Return to play after muscle injuries.

\section{References}

Árnason, Á., Sigurdsson, S. B., Gudmundsson, Á., Holme, I., Engebretsen, L., \& Bahr, R. (2004). Risk factors for injuries in football. Am J Sports Med, 32(1 Suppl), 5S-16S.

Askling, C., Saartok, T., \& Thorstensson, A. (2006). Type of acute hamstring strain affects flexibility, strength, and time to return to pre-injury level. Br J Sports Med, 40(1), 40-44.

Cohen, S. B., Towers, J. D., Zoga, A., Irrgang, J. J., Makda, J., Deluca, P. F., et al. (2011). Hamstring injuries in professional football players: magnetic resonance imaging correlation with return to play. Sports Health, 3(5), 423-430.

Comin, J., Malliaras, P., Baquie, P., Barbour, T., \& Connell, D. Return to competitive play after hamstring injuries involving disruption of the central tendon. $A m \mathrm{~J}$ Sports Med, 41(1), 111-115.

Connell, D. A., Schneider-Kolsky, M. E., Hoving, J. L., Malara, F., Buchbinder, R., Koulouris, G., et al. (2004). Longitudinal study comparing sonographic and $\mathrm{MRI}$ assessments of acute and healing hamstring injuries. AJR Am J Roentgenol, 183(4), 975-984.

Drawer, S., \& Fuller, C. W. (2002). Evaluating the level of injury in english professional football using a risk based assessment process. Br J Sports Med, 36, 446-451.

Eirale, C., Tol, J. L., Farooq, A., Smiley, F., \& Chalabi, H. (2012). Low injury rate strongly correlates with team success in Qatari professional football. $\mathrm{Br} \mathrm{J}$ Sports Med.

Ekstrand (2013a). Keeping your top players on the pitch: the key to football medicine at a professional level. Br J Sports Med, 47, 723-724.

Ekstrand (2013b). Playing too many matches is negative for both performance and player availability-results from the on-going UEFA onjury study. Deutsche Zeitschrift fur Sportmedicin, 64(1), 163-167.

Ekstrand, J., Askling, C., Magnusson, H., \& Mithoefer, K. (2013). Return to play after thigh muscle injury in elite football players: implementation and validation of the Munich muscle injury classification. Br J Sports Med, 47(12), 769-774.

Ekstrand, J., Healy, J. C., Walden, M., Lee, J. C., English, B., \& Hägglund, M. (2012). Hamstring muscle injuries in professional football: the correlation of MRI findings with return to play. Br J Sports Med, 46(2), 112-117.

Ekstrand, J., Hägglund, M., Kristenson, K., Magnusson, H., \& Waldén, M. (2013). Fewer ligament injuries but no preventive effect on muscle injuries and severe injuries: an 11-year follow-up of the UEFA Champions League injury study. $\mathrm{Br}$ J Sports Med, 47(12), 732-737.

Ekstrand, J., Hägglund, M., \& Waldén, M. (2011a). Epidemiology of muscle injuries in professional football (soccer). Am J Sports Med, 39(6), 1226-1232.

Ekstrand, J., Hägglund, M., \& Waldén, M. (2011b). Injury incidence and injury patterns in professional football: the UEFA injury study. Br J Sports Med, 45(7), 553-558.

Fuller, C. W., Ekstrand, J., Junge, A., Andersen, T. E., Bahr, R., Dvorak, J., et al. (2006). Consensus statement on injury definitions and data collection procedures in studies of football (soccer) injuries. Br J Sports Med, 40(3), 193201. 
Running title: Return to play after muscle injuries.

Gabbe, B. J., Bennell, K. L., Finch, C. F., Wajswelner, H., \& Orchard, J. W. (2006). Predictors of hamstring injury at the elite level of Australian football. Scand $J$ Med Sci Sports, 16(1), 7-13.

Gajhede Knudsen, M., Ekstrand, J., Magnusson, H., \& Maffulli, N. (2013).

Recurrence of Achilles tendon injuries in elite male football players is more common after early return to play: an 11-year follow-up of the UEFA Champions League injury study. Br J Sports Med, 47, 763-768.

Garrett, W. E., Jr. (1996). Muscle strain injuries. Am J Sports Med, 24(6(Suppl)), S28.

Gibbs, N. J., Cross, T. M., Cameron, M., \& Houang, M. T. (2004). The accuracy of $\mathrm{MRI}$ in predicting recovery and recurrence of acute grade one hamstring muscle strains within the same season in Australian Rules football players. $J$ Sci Med Sport, 7(2), 248-258.

Herring, S. A., Kibler, W. B., \& Putukian, M. The team physician and the return-toplay decision: a consensus statement-2012 update. Med Sci Sports Exerc, 44(12), 2446-2448.

Hägglund, M., Waldén, M., Bahr, R., \& Ekstrand, J. (2005). Methods for epidemiological study of injuries to professional football players: developing the UEFA model. Br J Sports Med, 39, 340-346.

Hägglund, M., Waldén, M., \& Ekstrand, J. (2006). Previous injury as a risk factor for injury in elite football: a prospective study over two consecutive seasons. $\mathrm{Br} \mathrm{J}$ Sports Med, 40, 767-772.

Hägglund, M., Waldén, M., Magnusson, H., Kristenson, K., Bengtsson, H., \& Ekstrand, J. (2013). Injuries affect team performance negatively in professional football: an 11-year follow-up of the UEFA Champions League injury study. Br J Sports Med, 47(12), 738-742.

Koulouris, G., \& Connell, D. (2006). Imaging of hamstring injuries: therapeutic implications. Eur Radiol, 16(7), 1478-1487.

Koulouris, G., Connell, D. A., Brukner, P., \& Schneider-Kolsky, M. (2007). Magnetic resonance imaging parameters for assessing risk of recurrent hamstring injuries in elite athletes. Am J Sports Med, 35(9), 1500-1506.

Müller-Wohlfahrt, H., Ueblacker, P., \& Hänsel, L. (2013). Muscle Injuries in Sports. Stuttgart: Thieme

Müller-Wohlfahrt, H., Hänsel, L., Mithoefer, K., Ekstrand, J., English, B., McNally, S., et al. (2012). Terminology and classification of muscle injuries in sport: The Munich consensus statement. Br J Sports Med, 47(6), 342-350.

Müller-Wohlfahrt, H., Ueblacker, P., \& Hänsel, L. (2010). Muskelverletzungen im Sport. Stuttgart: Georg Thieme Verlag KG.

Orchard, J. (1993). Orchard Sports Injury Classification System (OSICS). Sports Health, 11, 39-41.

Peetrons, P. (2002). Ultrasound of muscles. Eur Radiol, 12(1), 35-43.

Schneider-Kolsky, M. E., Hoving, J. L., Warren, P., \& Connell, D. A. (2006). A comparison between clinical assessment and magnetic resonance imaging of acute hamstring injuries. Am J Sports Med, 34(6), 1008-1015.

Shrier, I., Safai, P., \& Charland, L. (2014). Return to play following injury: whose decision should it be? Br J Sports Med, 48, 394-401.

Slavotinek, J. P. (2010). Muscle injury: the role of imaging in prognostic assignment and monitoring of muscle repair. Semin Musculoskelet Radiol, 14(2), 194-200.

Slavotinek, J. P., Verrall, G. M., \& Fon, G. T. (2002). Hamstring injury in athletes: using MR imaging measurements to compare extent of muscle injury with 
Running title: Return to play after muscle injuries.

amount of time lost from competition. AJR Am J Roentgenol, 179(6), 16211628.

Verrall, G. M., Kalairajah, Y., Slavotinek, J. P., \& Spriggins, A. J. (2006). Assessment of player performance following return to sport after hamstring muscle strain injury. J Sci Med Sport, 9(1-2), 87-90.

Verrall, G. M., Slavotinek, J. P., Barnes, P. G., Fon, G. T., \& Esterman, A. (2006). Assessment of physical examination and magnetic resonance imaging findings of hamstring injury as predictors for recurrent injury. J Orthop Sports Phys Ther, 36(4), 215-224.

Verrall, G. M., Slavotinek, J. P., Barnes, P. G., Fon, G. T., \& Spriggins, A. J. (2001). Clinical risk factors for hamstring muscle strain injury: a prospective study with correlation of injury by magnetic resonance imaging. Br J Sports Med, 35(6), 435-439; discussion 440.

Woods, C., Hawkins, R. D., Maltby, S., Hulse, M., Thomas, A., \& Hodson, A. (2004). The Football Association Medical Research Programme: an audit of injuries in professional football-analysis of hamstring injuries. Br J Sports Med, 38(1), 3641. 
Running title: Return to play after muscle injuries.

Table 1. Operational definitions

\begin{tabular}{ll}
\hline Injury & $\begin{array}{l}\text { Injury resulting from playing football and leading to a player being unable to fully participate } \\
\text { in future training or match play (i.e. time-loss injury). }\end{array}$ \\
Thigh muscle injury & $\begin{array}{l}\text { A traumatic distraction or overuse injury to the anterior or posterior thigh muscle groups } \\
\text { leading to a player being unable to fully participate in training or match play. }\end{array}$ \\
Rehabilitation & $\begin{array}{l}\text { A player was considered injured until team medical staff allowed full participation in training } \\
\text { and availability for match selection. }\end{array}$ \\
Lay-off & Number of days until the player resumed full team training. \\
Return-to-play & The decision-making process of returning an injured or ill athlete to practice or competition. \\
(RTP) & This ultimately leads to medical clearance of an athlete for full participation in sports \\
(Herring, Kibler, \& Putukian).
\end{tabular}

\section{Re-injury \\ Functional muscle disorders}

\section{Structural muscle disorders \\ Partial muscle injury - minor}

Injury of the same type and at the same site as an index injury occurring no more than two months after a player's return to full participation from the index injury.

Painful muscle disorder without evidence of muscle fibre damage.

Any acute indirect muscle disorder with macroscopic evidence of muscle fibre damage.

Structural muscle injury involving only Intra-Fascicle Tear. Acute, sharp pain often at muscletendon junction. Focal pain on palpation without palpable defect. No visible hematoma. Aggravation of pain by stretching and palpation. Intra-fascicle hematoma and focal muscle defect on imaging with intact surrounding fascia.

Partial muscle injury - moderate

Structural muscle injury involving Inter-Fascicle or Muscle Bundle Tear. Acute severe, stabbing pain often at muscle-tendon junction, often associated with fall from reflectory unloading. Palpable, defined defect in affected muscle, painful to touch and gentle stretch. Quickly developing, visible hematoma. Defect of muscle, fascia, and hematoma visible on imaging.

Subtotal/complete muscle injury/tendinous Structural muscle injury involving the subtotal (>90\%) or complete muscle diameter or complete tendinous avulsion. Acute severe pain ("someone kicked/hit me") and reflectory unloading. Severe pain with passive motion and palpation. Immediate functional deficit with avulsion development of extensive hematoma. Large palpable defect often at the muscle-tendon junction or retraction of avulsed muscle. Obvious muscle defect or tendinous avulsion and with hematoma formation is observed on imaging. 
Running title: Return to play after muscle injuries.

Table 2. Numbers and percentage of all muscle injuries as well as their mean and median lay off days before full participation in team training (injuries recorded between 2001 and 2013).

\begin{tabular}{|c|c|c|c|c|c|c|c|c|c|}
\hline OSICS 2 diagnose & $\mathbf{N}$ & $\%$ & $\begin{array}{r}\text { Mean } \\
\pm \text { SD }\end{array}$ & Median & IQR & Sum & $\begin{array}{l}\% \text { of } \\
\text { sum }\end{array}$ & $\begin{array}{r}\text { Re- } \\
\text { injuries }\end{array}$ & $\begin{array}{l}\% \text { re- } \\
\text { injuries }\end{array}$ \\
\hline $\begin{array}{l}\text { [TM1] Thigh strain/tear } \\
\text { hamstrings }\end{array}$ & 1922 & 34.3 & $18 \pm 19$ & 13 & 15 & 34000 & 38.2 & 311 & 16.2 \\
\hline $\begin{array}{l}\text { [GT1] Groin strain/pain } \\
\text { adductor group }\end{array}$ & 1190 & 21.2 & $15 \pm 22$ & 9 & 11 & 17314 & 19.5 & 192 & 16.1 \\
\hline $\begin{array}{l}\text { [TM2] Thigh strain/tear } \\
\text { quadriceps }\end{array}$ & 781 & 13.9 & $19 \pm 22$ & 12 & 16 & 15087 & 17.0 & 116 & 14.9 \\
\hline $\begin{array}{l}\text { [QM1] Calf muscle } \\
\text { strain }\end{array}$ & 652 & 11.6 & $18 \pm 16$ & 13 & 16 & 11547 & 13.0 & 84 & 12.9 \\
\hline $\begin{array}{l}{[T Y 1] \text { Thigh }} \\
\text { pain/hypertonia } \\
\text { hamstrings }\end{array}$ & 242 & 4.3 & $7 \pm 8$ & 5 & 5 & 1591 & 1.8 & 35 & 14.5 \\
\hline $\begin{array}{l}\text { [GT3] Hip } \\
\text { flexor/iliopsoas injury }\end{array}$ & 178 & 3.2 & $15 \pm 16$ & 11 & 15 & 2633 & 3.0 & 23 & 13.0 \\
\hline $\begin{array}{l}\text { [BM1] Hip/buttock } \\
\text { muscle strain/tear }\end{array}$ & 80 & 1.4 & $9 \pm 7$ & 8 & 6 & 732 & .8 & 1 & 1.3 \\
\hline [TM3] Thigh strain other & 80 & 1.4 & $16 \pm 31$ & 8 & 11 & 1311 & 1.5 & 10 & 12.5 \\
\hline $\begin{array}{l}\text { [TY2] Thigh } \\
\text { pain/hypertonia } \\
\text { quadriceps }\end{array}$ & 71 & 1.3 & $5 \pm 4$ & 4 & 3 & 352 & .4 & 12 & 16.9 \\
\hline $\begin{array}{l}\text { [GT5] Groin } \\
\text { tendinopathy/strain } \\
\text { other }\end{array}$ & 67 & 1.2 & $17 \pm 26$ & 9 & 18 & 1158 & 1.3 & 6 & 9.0 \\
\hline $\begin{array}{l}\text { [QY1] Calf muscle } \\
\text { pain/hypertonia }\end{array}$ & 66 & 1.2 & $6 \pm 5$ & 4 & 5 & 380 & .4 & 8 & 12.1 \\
\hline $\begin{array}{l}\text { [LM1] Lumbar muscle } \\
\text { strain }\end{array}$ & 63 & 1.1 & $7 \pm 6$ & 5 & 6 & 432 & .5 & 4 & 6.3 \\
\hline $\begin{array}{l}\text { [OM1] Abdomi-I muscle } \\
\text { strain }\end{array}$ & 50 & .9 & $13 \pm 10$ & 9 & 10 & 663 & .7 & 2 & 4.0 \\
\hline $\begin{array}{l}\text { [QM2] Lower leg muscle } \\
\text { strain }\end{array}$ & 43 & .8 & $19 \pm 20$ & 13 & 17 & 817 & .9 & 4 & 9.3 \\
\hline [LZ1] Lumbalgia/LBP & 13 & .2 & $7 \pm 7$ & 4 & 5 & 93 & .1 & 1 & 7.7 \\
\hline $\begin{array}{l}{[\mathrm{BY} 1] \mathrm{Hip} / \text { buttock }} \\
\text { muscle pain }\end{array}$ & 12 & .2 & $6 \pm 4$ & 5 & 6 & 71 & .1 & 3 & 25.0 \\
\hline $\begin{array}{l}\text { [KT5] Knee popliteus } \\
\text { tendinopathy/tear }\end{array}$ & 12 & .2 & $11 \pm 9$ & 9 & 11 & 135 & .2 & 1 & 8.3 \\
\hline $\begin{array}{l}\text { [NM1] Cervical muscle } \\
\text { strain }\end{array}$ & 12 & .2 & $5 \pm 3$ & 4 & 6 & 54 & .1 & 1 & 8.3 \\
\hline $\begin{array}{l}\text { [OT1] Abdomi-I rectus } \\
\text { tendinopathy }\end{array}$ & 11 & .2 & $15 \pm 13$ & 9 & 15 & 169 & .2 & 2 & 18.2 \\
\hline Other muscle injuries & 58 & 1.0 & $8 \pm 7$ & 6 & 7 & 466 & .5 & 5 & 8.6 \\
\hline Total & 5603 & 100.0 & $16 \pm 20$ & 11 & 14 & 89005 & 100.0 & 821 & 14.7 \\
\hline
\end{tabular}

$S D$, standard deviation; IQR, inter quartile range. Sum is cumulative lay off time. 
Running title: Return to play after muscle injuries.

Table 3. Lay-off days for hamstring muscle injuries and MRI grading according to Peetrons (injuries recorded between 2007 and 2013).

\begin{tabular}{|c|c|c|c|c|c|c|c|c|c|c|}
\hline Muscle & Grade & $\mathbf{N}$ & $\%$ & $\begin{array}{c}\text { Mean } \pm \\
\text { SD }\end{array}$ & $\begin{array}{l}\text { Medi } \\
\text { an }\end{array}$ & IQR & Sum & $\begin{array}{l}\% \text { of } \\
\text { sum }\end{array}$ & $\begin{array}{c}\text { Re- } \\
\text { injuries }\end{array}$ & $\begin{array}{c}\% \text { re- } \\
\text { injuries }\end{array}$ \\
\hline \multirow[t]{4}{*}{$\begin{array}{l}\text { Hamstring muscle } \\
\text { injuries }\end{array}$} & Grade 1 & 164 & 65.9 & $\begin{array}{r}18 \pm \\
15\end{array}$ & 15 & 14 & 3011 & 56.7 & 26 & 15.9 \\
\hline & Grade 2 & 77 & 30.9 & $\begin{array}{r}24 \pm \\
13\end{array}$ & 21 & 19 & 1825 & 34.4 & 12 & 15.6 \\
\hline & Grade 3 & 8 & 3.2 & $\begin{array}{r}60 \pm \\
57\end{array}$ & 37 & 59 & 476 & 9.0 & 1 & 12.5 \\
\hline & Total & 249 & 100.0 & $\begin{array}{r}21 \pm \\
19 \\
\end{array}$ & 17 & 15 & 5312 & 100.0 & 39 & 15.7 \\
\hline \multirow[t]{4}{*}{ Biceps femoris } & Grade 1 & 138 & 55.4 & $\begin{array}{r}19 \pm \\
16\end{array}$ & 15 & 14 & 2572 & 48.4 & 25 & 18.1 \\
\hline & Grade 2 & 63 & 25.3 & $24 \pm$ & 21 & 20 & 1497 & 28.2 & 12 & 19.0 \\
\hline & Grade 3 & 6 & 2.4 & $\begin{array}{r}71 \pm \\
63\end{array}$ & 55 & 81 & 426 & 8.0 & 1 & 16.7 \\
\hline & Total & 207 & 83.1 & $\begin{array}{r}22 \pm \\
20 \\
\end{array}$ & 16 & 15 & 4495 & 84.6 & 38 & 18.4 \\
\hline \multirow[t]{4}{*}{ Semimembranosus } & Grade 1 & 20 & 8.0 & $17 \pm$ & 14 & 10 & 330 & 6.2 & 1 & 5.0 \\
\hline & Grade 2 & 8 & 3.2 & $\begin{array}{r}23 \pm \\
15\end{array}$ & 20 & 17 & 181 & 3.4 & 0 & 0 \\
\hline & Grade 3 & 1 & .4 & $25 \pm$ & 25 & 0 & 25 & .5 & 0 & 0 \\
\hline & Total & 29 & 11.6 & $\begin{array}{r}18 \pm \\
10 \\
\end{array}$ & 16 & 12 & 536 & 10.1 & 1 & 3.4 \\
\hline \multirow[t]{4}{*}{ Semitendinosus } & Grade 1 & 6 & 2.4 & $\begin{array}{r}18 \pm \\
18\end{array}$ & 13 & 27 & 109 & 2.1 & 0 & 0 \\
\hline & Grade 2 & 6 & 2.4 & $\begin{array}{r}25 \pm \\
12\end{array}$ & 23 & 19 & 147 & 2.8 & 0 & 0 \\
\hline & Grade 3 & 1 & .4 & $25 \pm$ & 25 & 0 & 25 & .5 & 0 & 0 \\
\hline & Total & 13 & 5.2 & $\begin{array}{r}22 \pm \\
14 \\
\end{array}$ & 20 & 23 & 281 & 5.3 & 0 & 0 \\
\hline
\end{tabular}

$S D$, standard deviation; IQR, inter quartile range. Sum is cumulative lay off time.

Grade 1= oedema at MRI, Grade 2= partial tear on MRI, Grade 3= total tear on MRI. 
Running title: Return to play after muscle injuries.

Table 4. Lay-off days by quadriceps muscle injuries and MRI grading according to Peetrons (injuries recorde between 2007 and 2013).

\begin{tabular}{|c|c|c|c|c|c|c|c|c|c|c|}
\hline Muscle & Grade & $\mathbf{N}$ & $\%$ & $\begin{array}{l}\text { Mean } \\
\pm \text { SD }\end{array}$ & Median & IQR & Sum & $\begin{array}{l}\% \text { of } \\
\text { sum }\end{array}$ & $\begin{array}{c}\text { Re- } \\
\text { injuries }\end{array}$ & $\begin{array}{c}\% \text { re- } \\
\text { injuries }\end{array}$ \\
\hline \multirow[t]{4}{*}{$\begin{array}{l}\text { Quadriceps muscle } \\
\text { injuries }\end{array}$} & Grade 1 & $\begin{array}{l}5 \\
5\end{array}$ & 53.9 & $14 \pm$ & 12 & 9 & 772 & 30.3 & 5 & 9.1 \\
\hline & Grade 2 & $\begin{array}{l}4 \\
2\end{array}$ & 41.2 & $\begin{array}{r}33 \pm \\
29\end{array}$ & 22 & 29 & 1383 & 54.2 & 5 & 11.9 \\
\hline & Grade 3 & 5 & 4.9 & $\begin{array}{r}79 \pm \\
36\end{array}$ & 67 & 27 & 397 & 15.6 & 2 & 40.0 \\
\hline & Total & $\begin{array}{l}1 \\
0 \\
2 \\
\end{array}$ & 100.0 & $\begin{array}{r}25 \pm \\
26\end{array}$ & 17 & 19 & 2552 & 100.0 & 12 & 11.8 \\
\hline \multirow[t]{4}{*}{ Rectus femoris } & Grade 1 & $\begin{array}{l}4 \\
7\end{array}$ & 46.1 & $15 \pm$ & 12 & 10 & 692 & 27.1 & 5 & 10.6 \\
\hline & Grade 2 & $\begin{array}{l}3 \\
8\end{array}$ & 37.3 & $\begin{array}{r}33 \pm \\
29\end{array}$ & 22 & 27 & 1241 & 48.6 & 5 & 13.2 \\
\hline & Grade 3 & 5 & 4.9 & $\begin{array}{r}79 \pm \\
36\end{array}$ & 67 & 27 & 397 & 15.6 & 2 & 40.0 \\
\hline & Total & $\begin{array}{l}9 \\
0\end{array}$ & 88.2 & $\begin{array}{r}26 \pm \\
26 \\
\end{array}$ & 17 & 19 & 2330 & 91.3 & 12 & 13.3 \\
\hline \multirow[t]{4}{*}{ Vastus lateralis } & Grade 1 & 3 & 2.9 & $8 \pm$ & 8 & 3 & 25 & 1.0 & 0 & 0 \\
\hline & Grade 2 & 1 & 1.0 & $49 \pm$ & 49 & 0 & 49 & 1.9 & 0 & 0 \\
\hline & Grade 3 & - & - & - & - & - & - & - & - & - \\
\hline & Total & 4 & 3.9 & $\begin{array}{r}19 \pm \\
20 \\
\end{array}$ & 9 & 22 & 74 & 2.9 & 0 & 0 \\
\hline \multirow[t]{4}{*}{ Vastus medialis } & Grade 1 & 4 & 3.9 & $12 \pm$ & 13 & 10 & 48 & 1.9 & 0 & 0 \\
\hline & Grade 2 & 2 & 2.0 & $\begin{array}{r}42 \pm \\
57\end{array}$ & 42 & 80 & 84 & 3.3 & 0 & 0 \\
\hline & Grade 3 & - & - & - & - & - & - & - & - & - \\
\hline & Total & 6 & 5.9 & $\begin{array}{r}22 \pm \\
30 \\
\end{array}$ & 13 & 13 & 132 & 5.2 & 0 & 0 \\
\hline \multirow[t]{4}{*}{ Vastus intermedius } & Grade 1 & 1 & 1.0 & $\begin{array}{r}7 \pm \\
0\end{array}$ & 7 & 0 & 7 & .3 & 0 & 0 \\
\hline & Grade 2 & 1 & 1.0 & $9 \pm$ & 9 & 0 & 9 & .4 & 0 & 0 \\
\hline & Grade 3 & - & - & - & - & - & - & - & - & - \\
\hline & Total & 2 & 2.0 & $8 \pm$ & 8 & 2 & 16 & .6 & 0 & 0 \\
\hline
\end{tabular}

$S D$, standard deviation; IQR, inter quartile range. Sum is cumulative lay off time.

Grade 1= oedema at MRI, Grade 2= partial tear on MRI, Grade 3= total tear on MRI. 